\title{
Fourteen-Membered Macrocyclic Fe Complexes for Oxygen Reduction Catalysis Inspired by FeN 4 Centers Hosted by Graphene
}

\author{
Makoto Moriya,,${ }^{\dagger} \dagger \dagger$ Ryo Takahama, ${ }^{\dagger \dagger}$ Kazuki Kamoi, ${ }^{\dagger \dagger}$ Junya Ohyama, ${ }^{\ddagger}$ Shin Kawashima, ${ }^{\S}$ Ryoichi \\ Kojima, ${ }^{\S}$ Mariko Okadall, Teruaki Hayakawall and Yuta Nabae*\|॥ \\ †College of Science, Academic Institute, Shizuoka University, 836 Ohya, Suruga-ku, Shizuoka 422-8529, Japan \\ t'Department of Science, Graduate School of Integrated Science and Technology, Shizuoka University, 836 Ohya, Suruga- \\ ku, Shizuoka 422-8529, Japan \\ *Faculty of Advanced Science and Technology, Kumamoto University, 2-39-1 Kurokami, Chuo-ku, Kumamoto 860-8555, \\ Japan \\ ${ }^{\S}$ Inorganic \& Fluoric Chemistry R\&D Department, Asahi Kasei Corporation, 2767-11 Niihama, Shionasu, Kojima, Ku- \\ rashiki, Okayama 711-8510, Japan
}

"Department of Materials Science and Engineering, Tokyo Institute of Technology, 2-12-1 S8-26, Ookayama, Meguro-ku, Tokyo 152-8552, Japan

Supporting Information Placeholder

\begin{abstract}
For the globalization of polymer electrolyte fuel cells, the development of non-precious-metal (NPM) catalysts for oxygen reduction is extremely important. To date, many NPM catalysts have been synthesized by pyrolyzing Fe-, N-, and C-containing precursors, but they suffer from the density and uncertain chemical structure of their active sites. This study reports a 14-membered macrocyclic Fe complex, which was inspired by $\mathrm{FeN}_{4}$ centers in the pyrolyzed catalysts, whereas typical macrocyclic $\mathrm{MN}_{4}$ complexes have 16-membered rings. This 14-membered macrocycle has strong Fe-N bonding with an average bond distance of $1.90 \AA$, which has been evidenced by single-crystal X-ray diffraction, and is markedly shorter than that in porphyrin, $2.0 \AA$. Promising electrocatalytic activities for oxygen reduction have been demonstrated in both of acidic and basic media.
\end{abstract}

Catalysts for electrochemical oxygen reduction reaction (ORR) are important considering the involvement of ORR in polymer electrolyte fuel cells. In particular, ORR over non-precious metal (NPM)-derived catalysts is essential for the commercialization of polymer electrolyte fuel cells. ${ }^{1}$ The development of NPM ORR catalysts began with the discovery of the catalytic activity of Co(II) phthalocyanine for ORR by Jasinski in $1964 .^{2}$ Chemists were inspired by the similarity of this macrocyclic compound to natural enzymes, and many macrocyclic compounds were subsequently studied as ORR catalysts. ${ }^{3}$ However, their catalytic activity and durability were insufficient for use in the commercialization of fuel cell catalysts. In this context, since Jahnke et al. reported that the heat treatment of macrocyclic compounds can improve their ORR catalytic activity and durability, ${ }^{4}$ numerous attempts have been made to develop NPM cathode catalysts by pyrolyzing precursors containing transition metals (mainly Fe or $\mathrm{Co}$ ) and nitrogen and carbon sources. Although several recent studies have reported promising fuel cell performances with such pyrolyzed Fe/N/C cathode catalysts, ${ }^{5-9}$ their catalytic activities remain too low to replace Pt-based commercial cathode catalysts.

To date, pyrolyzed Fe/N/C catalysts have been regarded as more active than typical macrocyclic $\mathrm{MN}_{4}$ complexes such as Fe porphyrin. ${ }^{4}$ However, the exact reason for this difference in catalytic activity remained obscure because of the uncertain chemical structure of the pyrolyzed catalyst active sites. However, quite recently, significant progress in the direct microscopic observation of atomically dispersed $\mathrm{Fe}$ sites has been achieved, and $\mathrm{FeN}_{4}$ sites embedded in graphene sheets have been proposed. ${ }^{10-19}$ Interestingly, these $\mathrm{Fe}$ centers are thought to be surrounded by a 14-membered ring consisting of $\mathrm{C}$ and $\mathrm{N}$ atoms, whereas typical macrocyclic $\mathrm{MN}_{4}$ complexes have 16-membered rings (e.g., porphyrin and phthalocyanine). This has inspired our research group to focus on 14-membered macrocyclic Fe complexes as ORR catalysts. Understanding the difference between 14-membered and 16-membered ligands would result in a comprehensive understanding of pyrolyzed $\mathrm{Fe} / \mathrm{N} / \mathrm{C}$ catalysts and organic synthetic approaches for obtaining extremely active NPM cathode catalysts with high active site densities.

Scheme 1 shows the synthetic route of the 14-membered macrocyclic Fe complex prepared in the present study. A hexaaza macrocyclic ligand $\left(\mathrm{H}_{2} \mathrm{HAM}, \mathbf{1}\right)$ was prepared according to a literature method. ${ }^{20,21}$ Then, metalation of this ligand was performed by treating it with $\mathrm{FeBr}_{2}$ in $N, N$-dimethylformamide (DMF), and the resulting bluish powder was collected by filtration (complex 2 ). Aiming to obtain a pure complex, we attempted to recrystallize this ferrous complex in water, but the resulting crystalline precipitate was brownish, suggesting the existence of some amount of ferric complex $\quad\left(3, \quad\left[\left(\mathrm{H}_{2} \mathrm{O}\right)\left\{\mathrm{Fe}\left(\mathrm{H}_{2} \mathrm{HAM}\right)\right\}(\mu-\mathrm{O})\left\{\mathrm{Fe}\left(\mathrm{H}_{2} \mathrm{HAM}\right)\right\}(\mu-\right.\right.$ $\left.\left.\mathrm{O})\left\{\mathrm{Fe}\left(\mathrm{H}_{2} \mathrm{HAM}\right)\right\}\left(\mathrm{OH}_{2}\right)\right] \mathrm{Br} 6\right)$. 
Scheme 1. Synthetic route of 14-membered macrocyclic Fe complex
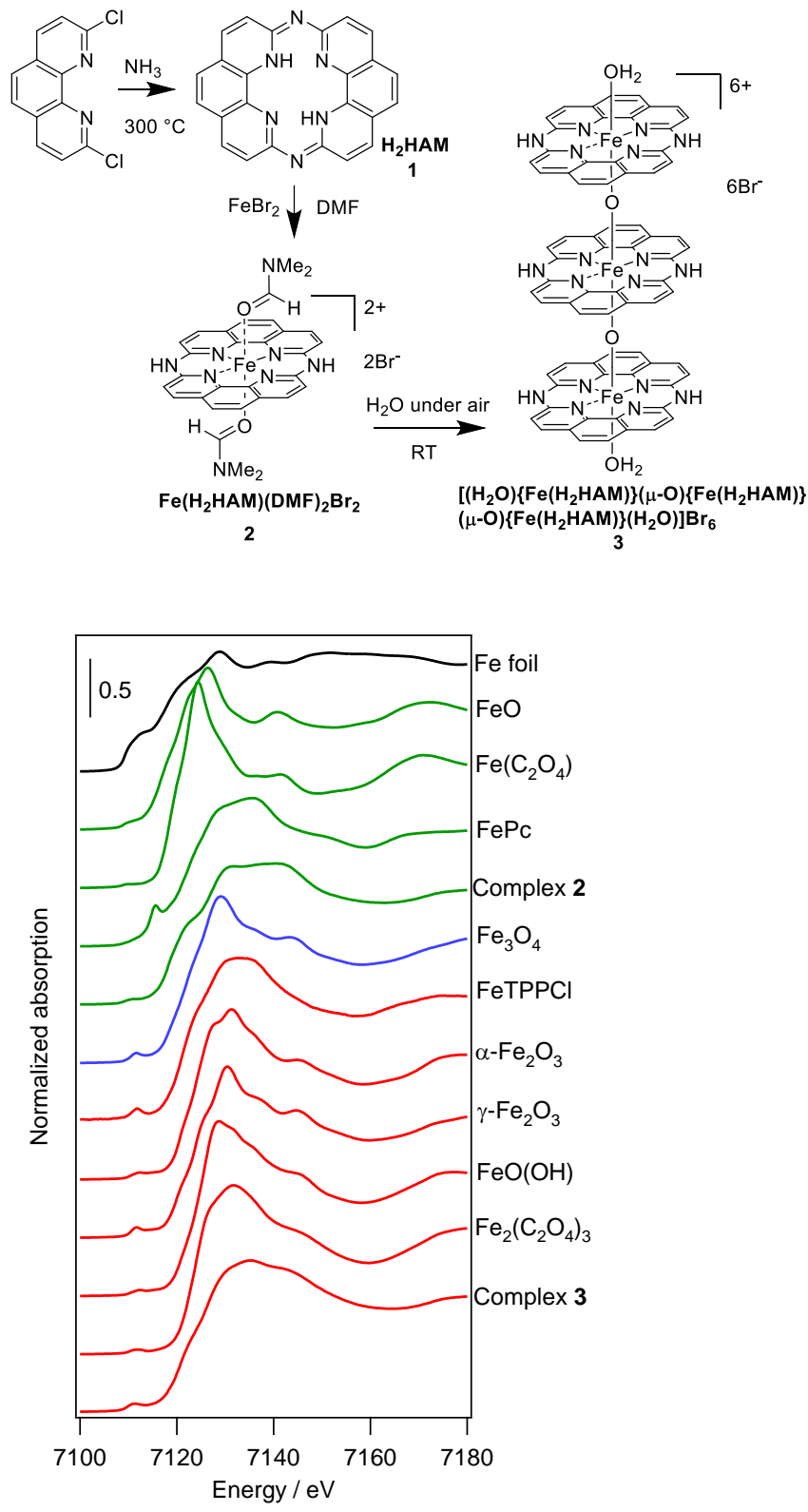

Figure 1 XANES spectra of complexes $\mathbf{2}$ and $\mathbf{3}$ together with those of various references including $\mathrm{Fe}$ foil, $\mathrm{FeO}, \mathrm{Fe}\left(\mathrm{C}_{2} \mathrm{O}_{4}\right), \mathrm{Fe}$ phthalocyanine (FePc), $\mathrm{Fe}_{3} \mathrm{O}_{4}, \mathrm{FeTPPCl}, \alpha-$ and $\gamma-\mathrm{Fe}_{2} \mathrm{O}_{3}, \mathrm{FeO}(\mathrm{OH})$, and $\mathrm{Fe}_{2}\left(\mathrm{C}_{2} \mathrm{O}_{4}\right)$.

The Fe valence states and structures of complexes $\mathbf{2}$ and $\mathbf{3}$ were investigated using $\mathrm{Fe} \mathrm{K}$-edge $\mathrm{X}$-ray absorption fine structure (XAFS) spectroscopy. Figure 1 shows the X-ray absorption near edge structure (XANES) spectra of complexes $\mathbf{2}$ and $\mathbf{3}$ together with those of various references including $\mathrm{Fe}$ foil, $\mathrm{FeO}, \mathrm{Fe}\left(\mathrm{C}_{2} \mathrm{O}_{4}\right)$, $\mathrm{Fe}$ phthalocyanine (FePc), $\mathrm{Fe}_{3} \mathrm{O}_{4}$, 5,10,15,20-tetraphenyl$21 \mathrm{H}, 23 \mathrm{H}$-porphyrin iron(III) chloride (FeTPPCl), $\alpha$ - and $\gamma-\mathrm{Fe}_{2} \mathrm{O}_{3}$, $\mathrm{FeO}(\mathrm{OH})$, and $\mathrm{Fe}_{2}\left(\mathrm{C}_{2} \mathrm{O}_{4}\right)$. The absorption edge energies at a normalized absorbance of 0.5 are plotted against the $\mathrm{Fe}$ formal valence in Figure 2. These results suggest that complexes $\mathbf{2}$ and $\mathbf{3}$ show absorption energy edges corresponding to $\mathrm{Fe}$ (II) and $\mathrm{Fe}(\mathrm{III})$ compounds, respectively. Thus, the valence states of $\mathrm{Fe}$ in complexes 2 and 3 were estimated to be $2+$ and (approximately) $3+$, respectively.
Oxidation of the Fe species in the recrystallization procedure is probably caused by oxygen molecules dissolved in water.

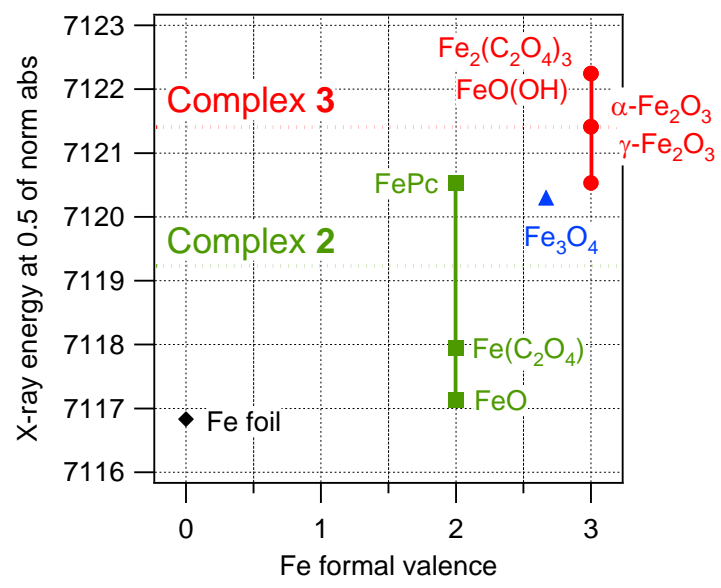

Figure 2 Relationship between Fe K-edge energy at 0.5 normalized absorption and $\mathrm{Fe}$ formal valence of the reference samples, where the energies of complexes $\mathbf{2}$ and $\mathbf{3}$ are superimposed.

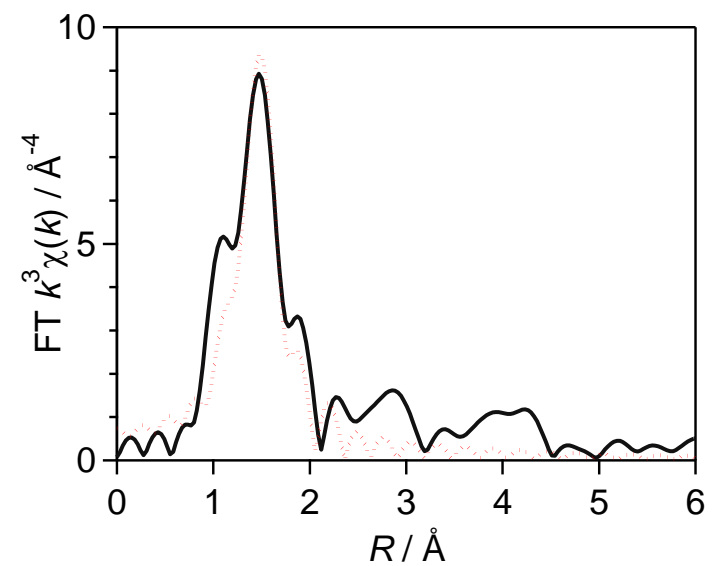

Figure 3 FT of Fe K edge EXAFS spectrum of complex 2 with the fitted line (red solid).

Table 1 Structural parameters of complex 2 evaluated by curve fitting analysis. ${ }^{a}$

\begin{tabular}{lllll}
\hline Atom & $N^{b}$ & $R^{c} / \AA$ & $\sigma^{2} d / \AA^{2}$ & $R$-factor \\
\hline $\mathrm{N}$ & 4 & $1.89(2)$ & $0.0030(10)$ & \\
$\mathrm{O}$ & 2 & $2.09(11)$ & $0.016(21)$ & 0.0379
\end{tabular}

${ }^{a}$ FT range: $3-14 \AA^{-1}$, curve fitting range: $1.0-2.0 \AA .{ }^{b}$ Coordination number. ${ }^{c}$ Atomic distance. ${ }^{d}$ Debye-Waller factor.

The detailed structure of complex 2 was studied by extended Xray adsorption fine structure (EXAFS), Fourier transform (FT) IR, and $\mathrm{CHN}$ elemental analyses. The structure was determined as a novel dicationic $\mathrm{FeN}_{4}$-type complex, $\left[\mathrm{Fe}\left(\mathrm{H}_{2} \mathrm{HAM}\right)(\mathrm{DMF})_{2}\right] \mathrm{Br}_{2}$, with two DMF molecules coordinated to the Fe center as displayed in Scheme 1. The FT of the Fe K-edge EXAFS for complex 2 and its curve-fitting results, which are summarized in Figure 3 and Table 1 , respectively, suggest that the Fe atom is coordinated to four 
$\mathrm{N}$ atoms at a distance of $1.89 \AA$ and two $\mathrm{O}$ atoms at a distance of $2.09 \AA$. In the FT-IR spectrum of complex 2 (Figure S1), strong absorptions due to $\mathrm{C}=\mathrm{O}$ stretching in $\mathrm{DMF}$ and $\mathrm{N}-\mathrm{H}$ bending in the ligand are present at 1677 and $1576 \mathrm{~cm}^{-1}$, respectively, the peak assignments of which were confirmed by density functional theory calculations (Figure S1). The results of the $\mathrm{CHN}$ elemental analysis of complex 2 also support the structure illustrated in Scheme 1.

The detailed structure of complex $\mathbf{3}$ was determined by singlecrystal X-ray diffraction (XRD) analysis at $-100{ }^{\circ} \mathrm{C}$. As shown in Figure 4, complex 3 was afforded as a triiron complex with three linearly arrayed $\mathrm{FeN}_{4}$ units. The three $\mathrm{FeN}_{4}$ units are bridged by two oxo ligands, and the $\mathrm{Fe}$ centers at the terminal $\mathrm{FeN}_{4}$ units are coordinated by aqua ligands. The trinuclear complex $\mathbf{3}$ exists as a hexavalent cation with six bromide counter ions. These structural features suggest that the formal oxidation numbers of the Fe centers of complex 3 are (III, IV, III). Note that the average valence of Fe (3.3+) presumed from this crystal structure does not contradict the valence state shown in Figure 2 (approximately $3+$ ). The FTEXAFS study (Figure S4) of complex 3 also supports the structure depicted in Figure 4.

The average bond length between $\mathrm{Fe}$ centers and $\mathrm{O}$ atoms at bridging oxo ligands was evaluated to be $1.76 \AA$, which is similar to that of a previously reported analogous complex with an $[\text { FeTPP }]_{2} \mathrm{O}$ framework. ${ }^{22}$ On the other hand, the average bond length between $\mathrm{Fe}$ and $\mathrm{N}$ atoms in the $\mathrm{FeN}_{4}$ moiety of complex 3 was calculated to be $1.90 \AA$. This Fe-N bond length is considerably shorter than that of Fe porphyrin complexes, which has been reported as approximately $2.0 \AA .{ }^{23}$ This result clearly shows that complex 3 with a 14-membered macrocyclic ligand forms stronger $\mathrm{Fe}$ $\mathrm{N}$ bonds compared with those in $\mathrm{FeN}_{4}$-type complexes with 16membered rings.

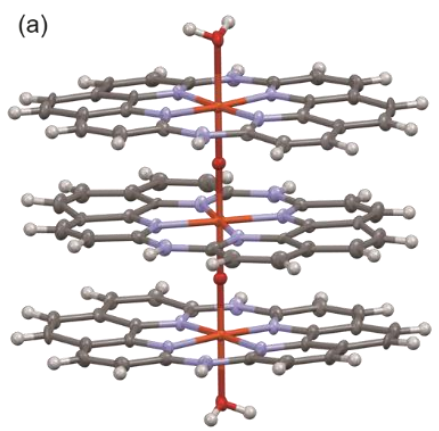

(b)

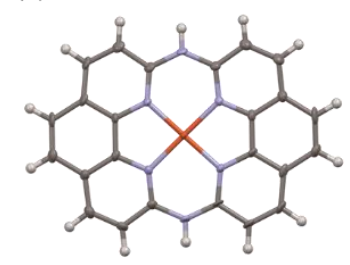

Figure 4. X-ray crystal structure of complex 3 (Fe: orange, C: gray, $\mathrm{N}$ : pale blue, O: red, H: pale gray): (a) side view of the complex with $\mathrm{FeN}_{4}$ units (the disordered unit of the 14-membered macrocyclic ligand at the center position, crystallization water, and bromide ions are omitted for clarity); (b) top view of the $\mathrm{FeN}_{4}$ unit at the terminal position of the triiron structure.

The ORR electrocatalytic performance of complexes $\mathbf{2}$ and $\mathbf{3}$ was evaluated by rotating ring-disk electrode (RRDE) voltammetry in acidic and basic media, and the results are summarized in Figure 5. The as-prepared complex powders were mixed with a Nafion solution and carbon black (Ketjen Black EC600JD), which respectively served as proton and electron conductors, in a solution of ethanol and water (50/50 vol\%), and the prepared ink was applied onto a glassy carbon disk electrode. Carbon black and FeTPPCl were also tested as a control and commercially available benchmark, respectively. In $0.5 \mathrm{M} \mathrm{H}_{2} \mathrm{SO}_{4}$, pristine carbon black shows no catalytic activity above $0.2 \mathrm{~V}$, while the commercial benchmark, FeTPPCl, shows some catalytic activity with an onset potential of $0.65 \mathrm{~V}$. Complexes $\mathbf{2}$ and $\mathbf{3}$ show higher onset potentials at approximately $0.75 \mathrm{~V}$ and extremely low selectivity toward $\mathrm{H}_{2} \mathrm{O}_{2}$, whereas FeTPPCl showed considerable $\mathrm{H}_{2} \mathrm{O}_{2}$ formation at $0.3-0.6 \mathrm{~V}$. The current density in the diffusion-limited region (below $0.5 \mathrm{~V}$ ) is better with complex $\mathbf{2}$ than that with complex $\mathbf{3}$. This is probably because the dispersion of complex $\mathbf{3}$ in the catalyst ink was poor, and thus a uniform catalyst layer could not be fabricated. Such poor dispersion presumably arises from the relatively large crystallites of complex 3, as they were suitable for single-crystal XRD. In 0.1 $\mathrm{M} \mathrm{KOH}$, the ORR catalytic activities of complexes $\mathbf{2}$ and $\mathbf{3}$ are excellent with an onset potential of approximately $0.95 \mathrm{~V}$, and the current density reaches the diffusion-limited current with a small over potential. The complexes also show a clear advantage in current density at $0.5-0.9 \mathrm{~V}$ against $\mathrm{FeTPPCl}$. The selectivity toward $\mathrm{H}_{2} \mathrm{O}_{2}$ was extremely small with complexes $\mathbf{2}$ and $\mathbf{3}$.

To the best of our knowledge, this is the first report demonstrating the advantage of an aromatic 14-membered macrocyclic Fe complex, which was inspired by an $\mathrm{FeN}_{4}$ moiety embedded in graphene, against 16-membered macrocyclic Fe complexes in terms of ORR electrocatalytic activity. Although the exact reason for this enhanced catalytic activity with a 14-membered ring still requires clarification, the strong coordination of $\mathrm{N}$ atoms to the Fe center (1.90 ̊ with a 14-membered ring against $2.0 \AA$ A with a 16-membered ring) might affect the electronic structure of the Fe center and contribute to enhancing the catalytic activity. Further studies will be performed to clarify the durability and reaction mechanism of the 14-memberd macrocyclic Fe complexes, and to develop truly active and stable Fe complexes by tuning the chemical structure of these 14-membered macrocyclic ligands. (a) $0.5 \mathrm{M} \mathrm{H}_{2} \mathrm{SO}_{4}$

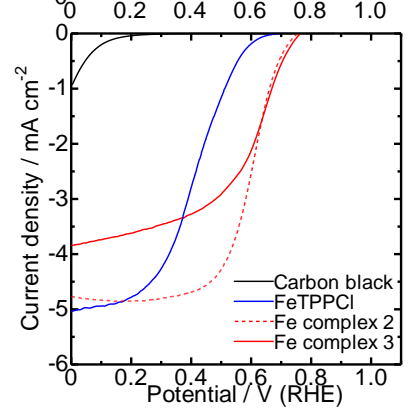

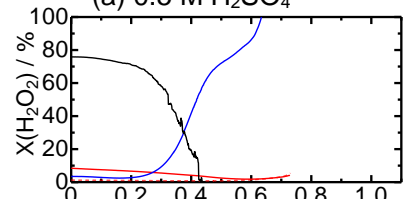

(b) $0.1 \mathrm{M} \mathrm{KOH}$

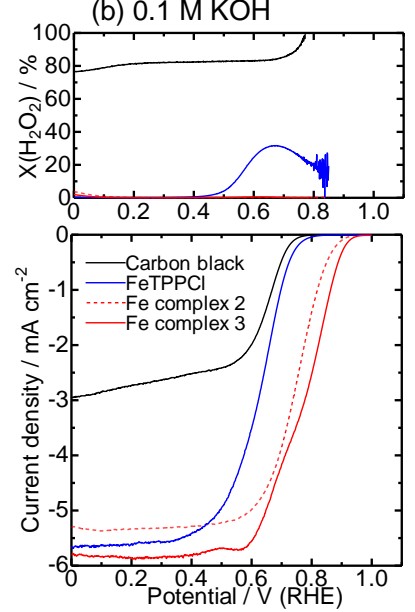

Figure 5. RRDE voltammograms of the Fe complexes in (a) $0.5 \mathrm{M}$ $\mathrm{H}_{2} \mathrm{SO}_{4}$ and (b) $0.1 \mathrm{M} \mathrm{KOH}$. Rotation: $1600 \mathrm{rpm}$.

\section{ASSOCIATED CONTENT}

\section{Supporting Information}

The Supporting Information is available free of charge.

Experimental details and additional spectroscopic results (PDF)

\section{AUTHOR INFORMATION}

\section{Corresponding Author \\ *nabae.y.aa@m.titehc.ac.jp}

\section{ACKNOWLEDGMENT}


This study was financially supported by the New Energy and Industrial Technology Development Organization (NEDO). XAFS measurement was performed at the BL5S1 at the Aichi Synchrotron Radiation Center in Japan (Proposal No. 201805085 and 201904003).

\section{REFERENCES}

(1) Chen, Z.; Higgins, D.; Yu, A.; Zhang, L.; Zhang, J. A Review on Non-Precious Metal Electrocatalysts for PEM Fuel Cells. Energy and Environ. Sci., 2011, 4, 3167-3192.

(2) Jasinski, R. A. New Fuel Cell Cathode Catalyst. Nature 1964, 201, 1212-1213.

(3) Masa, J.; Ozoemena, K. I.; Schuhmann, W.; Zagal, J. H. Fundamental Studies on the Electrocatalytic Properties of Metal Macrocyclics and Other Complexes for the Electroreduction of $\mathrm{O}_{2}$. In Lecture Notes in Energy; Springer, London, 2013; Vol. 9, pp $157-212$. Jahnke, H.; Schönborn, M.; Zimmermann, G. Organic Dyestuffs as Catalysts for Fuel Cells. In Physical and Chemical Applications of Dyestuffs; Springer-Verlag: Berlin/Heidelberg, 1976; Vol. 61, pp 133-181.

(5) Proietti, E.; Jaouen, F.; Lefèvre, M.; Larouche, N.; Tian, J.; Herranz, J.; Dodelet, J.-P. Iron-Based Cathode Catalyst with Enhanced Power Density in Polymer Electrolyte Membrane Fuel Cells. Nat. Commun. 2011, 2, 416.

(6) Strickland, K.; Miner, E.; Jia, Q.; Tylus, U.; Ramaswamy, N.; Liang, W.; Sougrati, M.-T.; Jaouen, F.; Mukerjee, S. Highly Active Oxygen Reduction Non-Platinum Group Metal Electrocatalyst without Direct Metal-Nitrogen Coordination. Nat. Commun. 2015, 6, 7343 .

(7) Nabae, Y.; Nagata, S.; Hayakawa, T.; Niwa, H.; Harada, Y.; Oshima, M.; Isoda, A.; Matsunaga, A.; Tanaka, K.; Aoki, T. PtFree Carbon-Based Fuel Cell Catalyst Prepared from Spherical Polyimide for Enhanced Oxygen Diffusion. Sci. Rep. 2016, 6, 23276. https://doi.org/10.1038/srep23276.

(8) Banham, D.; Kishimoto, T.; Zhou, Y.; Sato, T.; Bai, K.; Ozaki, J.; Imashiro, Y.; Ye, S. Critical Advancements in Achieving High Power and Stable Nonprecious Metal Catalyst-Based MEAs for Real-World Proton Exchange Membrane Fuel Cell Applications. Sci. Adv. 2018, 4, 1-7.

(9) Wan, X.; Liu, X.; Li, Y.; Yu, R.; Zheng, L.; Yan, W.; Wang, H.; Xu, M.; Shui, J. Fe-N-C Electrocatalyst with Dense Active Sites and Efficient Mass Transport for High-Performance Proton Exchange Membrane Fuel Cells. Nat. Catal. 2019, 2, 259-268.

(10) Chung, H. T.; Cullen, D. A.; Higgins, D.; Sneed, B. T.; Holby, E. F.; More, K. L.; Zelenay, P. Direct Atomic-Level Insight into the Active Sites of a High-Performance PGM-Free ORR Catalyst. Science 2017, 357, 479-484.

(11) Chen, Y.; Li, Z.; Zhu, Y.; Sun, D.; Liu, X.; Xu, L.; Tang, Y. Atomic Fe Dispersed on N-Doped Carbon Hollow Nanospheres for High-Efficiency Electrocatalytic Oxygen Reduction. $A d v$. Mater. 2019, 31, 1806312.
(12) Liu, Y.; Huang, B.; Zhang, X.; Huang, X.; Xie, Z. In-Situ Fabrication of Nitrogen-Doped Carbon Nanosheets Containing Highly Dispersed Single Iron Atoms for Oxygen Reduction Reaction. J. Power Sources 2019, 412, 125-133.

(13) Li, J.-C.; Cheng, M.; Li, T.; Ma, L.; Ruan, X.; Liu, D.; Cheng, H.-M.; Liu, C.; Du, D.; Wei, Z.; Lin, Y.; Shao, M. Carbon Nanotube-Linked Hollow Carbon Nanospheres Doped with Iron and Nitrogen as Single-Atom Catalysts for the Oxygen Reduction Reaction in Acidic Solutions. J. Mater. Chem. A 2019, 7, 14478-14482.

(14) Zhang, H.; Ding, S.; Hwang, S.; Zhao, X.; Su, D.; Xu, H.; Yang, H.; Wu, G. Atomically Dispersed Iron Cathode Catalysts Derived from Binary Ligand-Based Zeolitic Imidazolate Frameworks with Enhanced Stability for PEM Fuel Cells. J. Electrochem. Soc. 2019, 166, F3116-F3122.

(15) Ye, G.; He, Q.; Liu, S.; Zhao, K.; Su, Y.; Zhu, W.; Huang, R.; $\mathrm{He}, \mathrm{Z}$. Cage-Confinement of Gas-Phase Ferrocene in Zeolitic Imidazolate Frameworks to Synthesize High-Loading and Atomically Dispersed Fe-N Codoped Carbon for Efficient Oxygen Reduction Reaction. J. Mater. Chem. A 2019, 7, 1650816515.

(16) Chen, M.; He, Y.; Spendelow, J. S.; Wu, G. Atomically Dispersed Metal Catalysts for Oxygen Reduction. ACS Energy Lett. 2019, 4, 1619-1633.

(17) Wang, Y.; Wang, M.; Zhang, Z.; Wang, Q.; Jiang, Z.; Lucero, M.; Zhang, X.; Li, X.; Gu, M.; Feng, Z.; Liang, Y. Phthalocyanine Precursors To Construct Atomically Dispersed Iron Electrocatalysts. ACS Catal. 2019, 9, 6252-6261.

(18) Wang, C.; Chen, W.; Xia, K.; Xie, N.; Wang, H.; Zhang, Y. Silk-Derived 2D Porous Carbon Nanosheets with AtomicallyDispersed Fe- $\mathrm{N}_{x}$-C Sites for Highly Efficient Oxygen Reaction Catalysts. Small 2019, 15, 1804966.

(19) Zhang, G.; Jia, Y.; Zhang, C.; Xiong, X.; Sun, K.; Chen, R.; Chen, W.; Kuang, Y.; Zheng, L.; Tang, H.; Liu, W.; Sun, X.; Lin, W.-F.; Dai, H. A General Route via Formamide Condensation to Prepare Atomically Dispersed Metal-Nitrogen-Carbon Electrocatalysts for Energy Technologies. Energy Environ. Sci. 2019, 12, 1317-1325.

(20) Ogawa, S. Preparation of Macrocyclic Compounds by Thermal Dimerization of 1,10-Phenanthroline Derivatives. J. Chem. Soc. Perkin Trans. 1 1977, No. 2, 214-216.

(21) Wang, W.-J.; Chuang, K.-S.; Luo, C.-F.; Liu, H.-Y. An Efficient One-Pot Route to an Aza-Bridged Bis-Phenanthroline Macrocyclic Compound. Tetrahedron Lett. 2000, 41, 8565-8568.

(22) Hoffman, A. B.; Collins, D. M.; Day, V. W.; Fleischer, E. B.; Srivastava, T. S.; Hoard, J. L. The Crystal Structure and Molecular Stereochemistry of $\mu$-Oxo-Bis $[\alpha, \beta, \gamma, \delta$-TetraphenylporphinatoironCIII)]. J. Am. Chem. Soc. 1972, 94, 36203626.

(23) Peters, M. K.; Näther, C.; Herges, R. Crystal Structure of Bis(4Methoxypyridine- $\kappa \mathrm{N})($ Meso-5,10,15,20-Tetraphenylporphyrinato- $\left.\kappa^{4} N, N^{\prime}, N^{\prime \prime}, N^{\prime \prime \prime}\right)$ Iron(III) Perchlorate. Acta Crystallogr. Sect. E Crystallogr. Commun. 2019, 75, 762-765. 


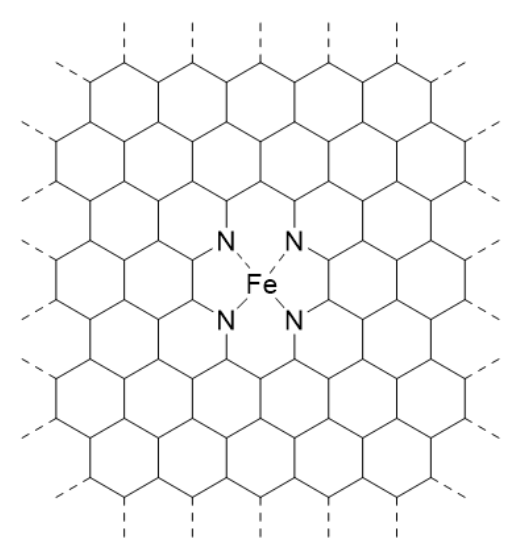

$\mathrm{FeN}_{4}$ center in graphene
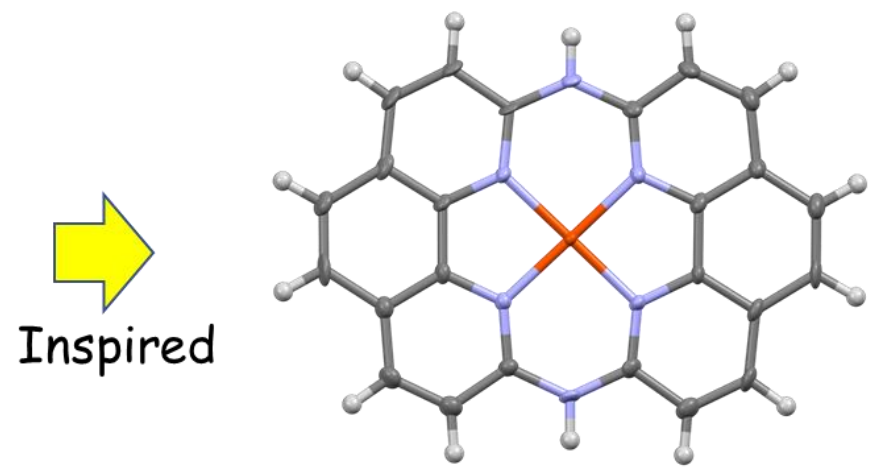

14-membered macrocyclic Fe complex for oxygen reduction catalysis 